\title{
DISCLAIMER
}

This report was prepared as an eccount of work aponeored by an agency of the United Stutea Government. Noither the Uniled Stalea Government nor any agency thereof, nor any of their employoea, makes any warranty, expreas or Implied, or ansumes any logal liabliticy or reaponalbllity for the aceuracy, completonea, or usofulneas of any information, arparatus, product, or process disclosed, or ropresents that lte use would not Infringe privately owned rights. Reference heroin to any apeelfic commercial product, proces, of corvise by trade name, Irademark, manufacturer, or otherwive does not necesustily conutlitute or imply It endornement. recommendation, or favoring by the United Stated Government or any agency thereof. The viows and opinions of authois oxpreaced herein do not necesuarlly itate or reflect thase of the United States Government or any agency thereof. 


\section{A SOLID STATE DIRECTIONAL GAMMA DETECTOR}

William Baird, Wesley P. Unruh, George O. Bjarke and Paul Beauchamp Los Alamos National Laboratory

\section{ABSTRACT}

A solld-state gamma-ray detector has been developed which exhibits directionality. Four PIN diode detectors are backed with Pb and artanged in a square array which exhibits an angular response to gamma rays. The high-z material provides directionality and also enhances the sensitivity of the detectors to high-energy gammas by means of the $x$-ray fluorescence. accompanying photon Interactions in the backing. The array responses are used to identify the quadrant containing the source and obtain the radiation level. Ratios of the counting rates in opposite pairs of detectors are used to determine the angular position of the source within the quadrant.

\section{INTRODUCTION}

The availability of PIN diode detectors ${ }^{1}$ with reasonabie sensitivity to $x$-rays and low-energy gamma rays has made possible the development of conventent, low-power, portable radiation-measuring instruments. The addition of microprocessor control leads to a class of hand-held instruments which are capable of ldentifying and measuring radiation sources automatically under a wide variety of conditions. Thls capabllity can be greatly extended, as in the 
Radiation Mapping System (Ranger) ${ }^{2}$ developed at Los Alamos, by telemetering radiation levels measured by such instruments to a ranging system capable of directly plotting the radiation contours of a site belng surveyed. In this and other applications, it would be very beneficial to have a detector capable of rapidly and conveniently determining both the radiation level and the direction to the source being detected. While collimated detectors can be used In this appliation, it would be advantageous to have a detector capable of measuring both the radiation intensity and the direction of the source in a single acquisition cycle. The device described below is a prototype capable of doing this, and is sufficiently light, low-powered and small to be produced as a self-contained hand-held field instrument. The computations required to obtain directional information from the detector count rates can be hand led by the microcomputer used to manage the other functions of such portable instruments.

THE DETECTOR ARRAY

The accurate location of a gamma-ray source by means of a single detector requlred a collimator with sufflciently narrow acceptance angle to satisfy the particular resolution requlrements. In contrast, If one uses an array of detectors, each one 1 s requlred to exhibit only a modest angular response and front/back ratlo, provided al I counts can simultaneously be acquired and used in a computation of the position of the source. Because of the avallablitty of PIN dlodes with reasonable sensltivitles, it is feasible to bulld such an array which is sultable for fleld-portablo use. 
Our prototype detector consists of a planar array of PIN diodes mounted on the faces of a $\mathrm{Pb}$ cube. Two versions have been constructed. The first consisted of 4 PIN diodes on the faces of a 1 $\mathrm{cm}$ cube. The second version has 4 PIN diodes on each face of a hollow Pb cube. In both cases, the $\mathrm{Pb}$ thickness is $1 \mathrm{~cm}$ which, for ${ }^{60}$ Co gamma rays, provides a front/back ratio of approximately 3 for opposing detectors. The seconci version is shown in Fig. 1. The Pb cube is partly hidden under the teflon mounting plate, and it is inserted into the detector package which has the PIN diodes mounted on the inside surfaces of the teflon block. The angular response function for each detector is approximated quite well by a biased $\cos ^{2}(\theta / 2)$ function.

The sensitivity of PIN diodes decreases rapldly with energy, but it can be enhanced at higher energies by backing the diodes with a high-z material. Measurements of the sensitlvity of the PIN diodes as a function of the thickness of the high-z backing show a significant enhancement of the intrinslc diode sensitivity for gamma-ray energles above $100 \mathrm{keV}$. Thls enhancement: is provided by the $x$-ray fluorescence accompanying the gamma-ray interactions in the attenuator which, In the case of $\mathrm{Pb}$, is at $72 \mathrm{KeV}$, and by low-energy backscattered Compton photons. This response is illustrated in Fig. 2, whlch shows the pulse helght spectra for ${ }^{57}$ Co and ${ }^{50}$ Co sources. Both spectra show the e. 'ancement at: $72 \mathrm{keV}$ due to fluorescence In the backing. For gamma-ray energles above 100 kev, this enhoncement reaches a factor of 2 at about $1 \mathrm{~cm}$ thickress of $\mathrm{Pb}$. Since the diode sensitivity rises sharply below $\theta 0$ kev, a lighter attenuating inaterlal may prove to be auvantigeous. 


\section{ELECTRONICS AND COMPUTATIONS}

The electronics package constructed to implement this scheme consists of two units for the detector and signal processing electronics connected via a serial port to a sinall microcomputer which implements the directional algorithm and displays the results graphically. It was expedient to separate the analog and digital sections of the signal processing electronics because of the high noise sensitivity of the charge-sensitive amplifiers used to amplify the signal from the detectors.

The detector package sontains the detectors and assoclated analog electronics. Each of the four sides of the detector consists of 4 PIN diodes paired into two charge-sensitive preamplifiers which are summed by a simple two-stage RC shaping amplifier. Due to the small charge generuted in each detector, it was found necessary to preselect the input FETs for each preamplifier for low nolse characteristics and to adjust the amplifier chains for roughly equivalent gains.

Measurements of the effects of paralleling PIN diodes into a single preamplifler show that the charge generated by an event in a single dlode is partially diverted by the paralleled junctions. The reduction in galn degrades the signal-to-nolse ratio. In the interest of increasing sensltivity, while minimizing elcctronics aid preserving a reasonable signal-to-nolse ratio, it was found that 2 diodes connected to a preamplifler was nearly optimum. The clicuit board contalning the preamplifiers and shaplng amplifiors was constructed as an Integral part of the detector package to minimize 
microphonic noise. This detector package and the associated microprocessor board and power source are shown in Fig. 1.

The digital electronics package consists of a microprocessor which communicates the counts to the microcomputer which are accumulated in 4 counters during a variable acquisition period. The 4 analog signals from the detector package are shaped and discriminated by comparators which connect to the counters. Thus, each acquisition cycle results in 4 separate count totals for the 4 individual faces. In our prototype instrument, these 4 counts are sent via a RS232 IIne to a small mlcrocomputer for computition and graphic display. (These tasks could easily be handled in a violinist ${ }^{3}$ package of the type used in many of our portable instruments and the results displayed on a large liquid crystal graphics display designed stecifically for this application.) The scftware performs essentially three tasks: First, the 4 counts are compared and the quadrant facing the source is identified. Totalizing the counts provides a measurement of the intensity being received from this quadrant. Second, the counts are identified in palrs as belonging to the detectors most nearly aligned along the source direction and those transverse to thls direction. The ratios of these pairs of counts are then calculated. Third, these two ratios are compared with a look-up table containing ratios measured from the angular response of the detector array and the angles Identifled for these two ratios. Becalise of statistics, these two angles rarely agree exactly, so a weighted average is taken whlch takes into account the reduced sensitivity to angle of the count ratio as the scurce position approaches a direction normal to one 
face. (In effect, the two side detectors determine the angle when the source is normal to a face.) This average angle and the measured intensity are used to produce a logarithmic polar plot identifying the source direction with respert to the array.

\section{DISCUSSION}

The prototype detector described here has been set up to provide angular detection of ${ }^{60} \mathrm{Co}$ (and, with less accuracy, ${ }^{137} \mathrm{Cs}$ ) gamma rays. Its characteristics are such that straightforward design modifications should make it generally applicable to a range of energies. The angular response of the array depends upon gamma-ray erergy, and its sensitivity is a strong functior of energy as well. since the detector pulse-height spectrum contains very lictle onergy information, some means of determining the appropriate angular function for the gamma energy being detected is necessary. rino approach whlch we are investigating is to shim the detector package so that all gamma-ray energies over a range of interest produce essentially the same angular functicn. inis procedure may also Improve the energy response of the array. On the other hand, the storage of several sets of angular functions appropriate to several different energy ranges presents no problem. One way to obtain energy information about the gamma fleld being measured would de to use a fifth detector which has some energy resolution to provide the constants needed (Eroin counts In several ROIs) to use the appropriate angular functions and electronically shim the detector response. Another more direct method would te to use an array constructed from detectors which exhlbit energy resolution and then calculate the 
angular ratios separately in each of several energy ranges. This scheme, if Implemented with scintillation detectors, would extend the sensitivity of the device to background levels and might be capable of lociting several sources of distinctly different gamma-ray energy. An attractive way to do this is to use CsI scintillators coupled to photodiodes, and we are presently investigating this approach.

Experience with this protorype shows that colinting statistics of approximately 108 is sufficient to result in an angular definition of plus or minus 10 degrees, with precision increasing as the statistics improve. In order to provide as much precision as possible, an exponential running average is kept for each count, so the indicated angular direction changes gradually over several acquisition cycles. The sensitivity of the detector is such that (for ${ }^{60}$ Co) a field of 1 $\mathrm{mR} / \mathrm{hr}$ produces an average of $20 \mathrm{cps}$. We anticipate that a detector constructed with CsI scintillators and PIN diodes would be significantly more sensitive while providing the energy resolution to allow us to obtain angular discrimination over a wider range of gamma-range energies.

\section{ACKNOWLEDGEMENTS}

The authors wish to thank Faustin Trujillo for providing the mechanical design and fabrication, Kathleen Dolberg for graphic design and photographlc rrordination, B. J. Vanlyssel for help with the electronic fabrication, and Esther Dorsey for help in producing the manuscript. 


\section{REFERENCES}

1. Hamamatsu Corp., 420 South Ave., Middlesex, New Jersey 08946 .

2. G. M. Worth, J. M. Crowell, A. D. Meddles, J. D. Jarrett, M. A. Wolf, C. J. Umbarger, and Chris Moyei, IEEE Trans. Nucl. Sci. NS-32 (1984) 957 .

3. Michael A. Wolf and Hugh C. Staley, IEEE Trans. Nucl. Sci. NS-32 (1984) 82 .

\section{EIGURE CAPTIONS}

Fig. 1. Disassembled view of the instrument.

Fig. 2. Spectral response of the detector to ${ }^{60}$ Co and ${ }^{57}$ Co gamma rays. The enhancement from $72 \mathrm{keV} \mathrm{Pb}$ fluorescence is visible in both spectra. 


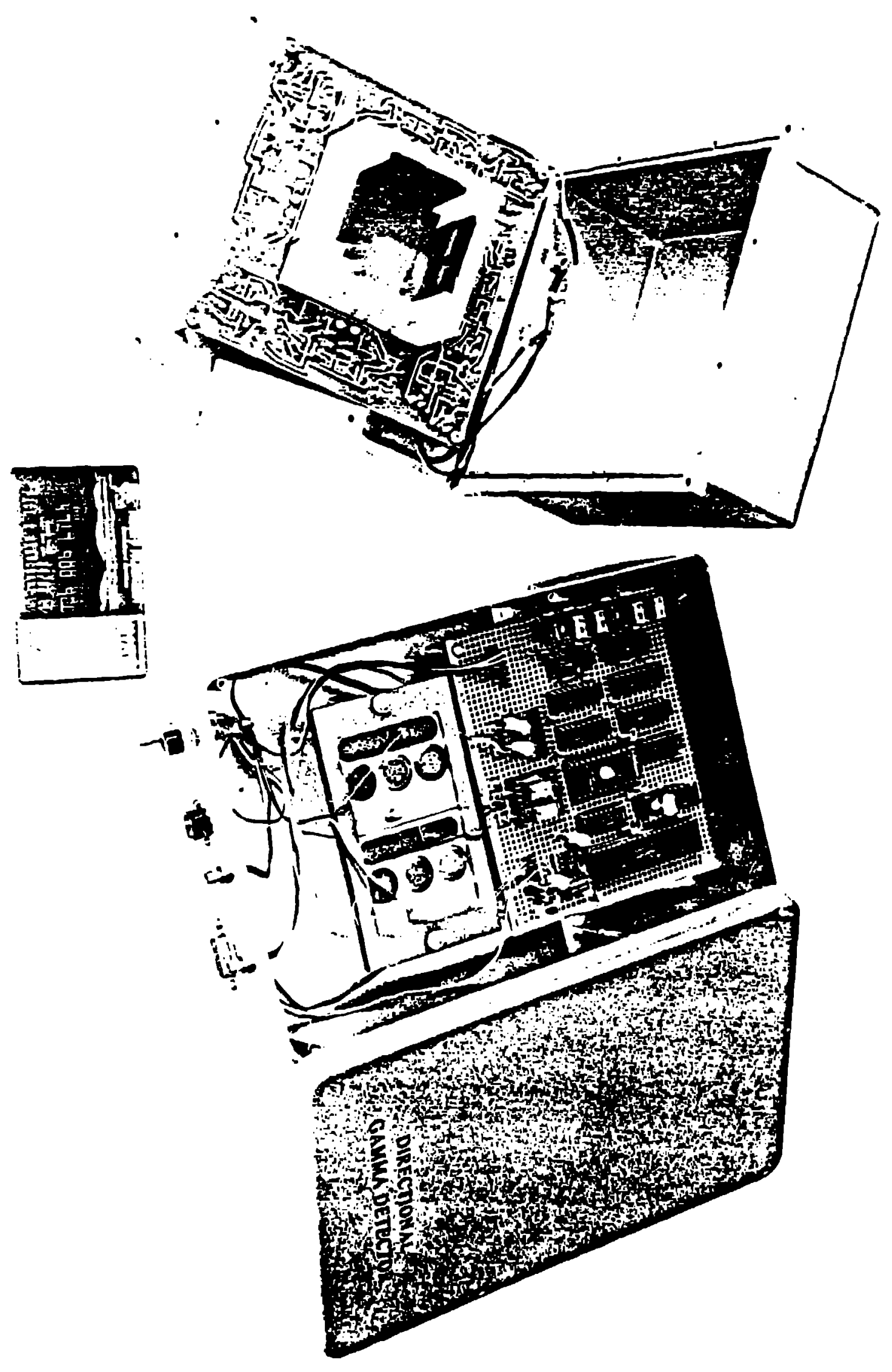

FIG 1 


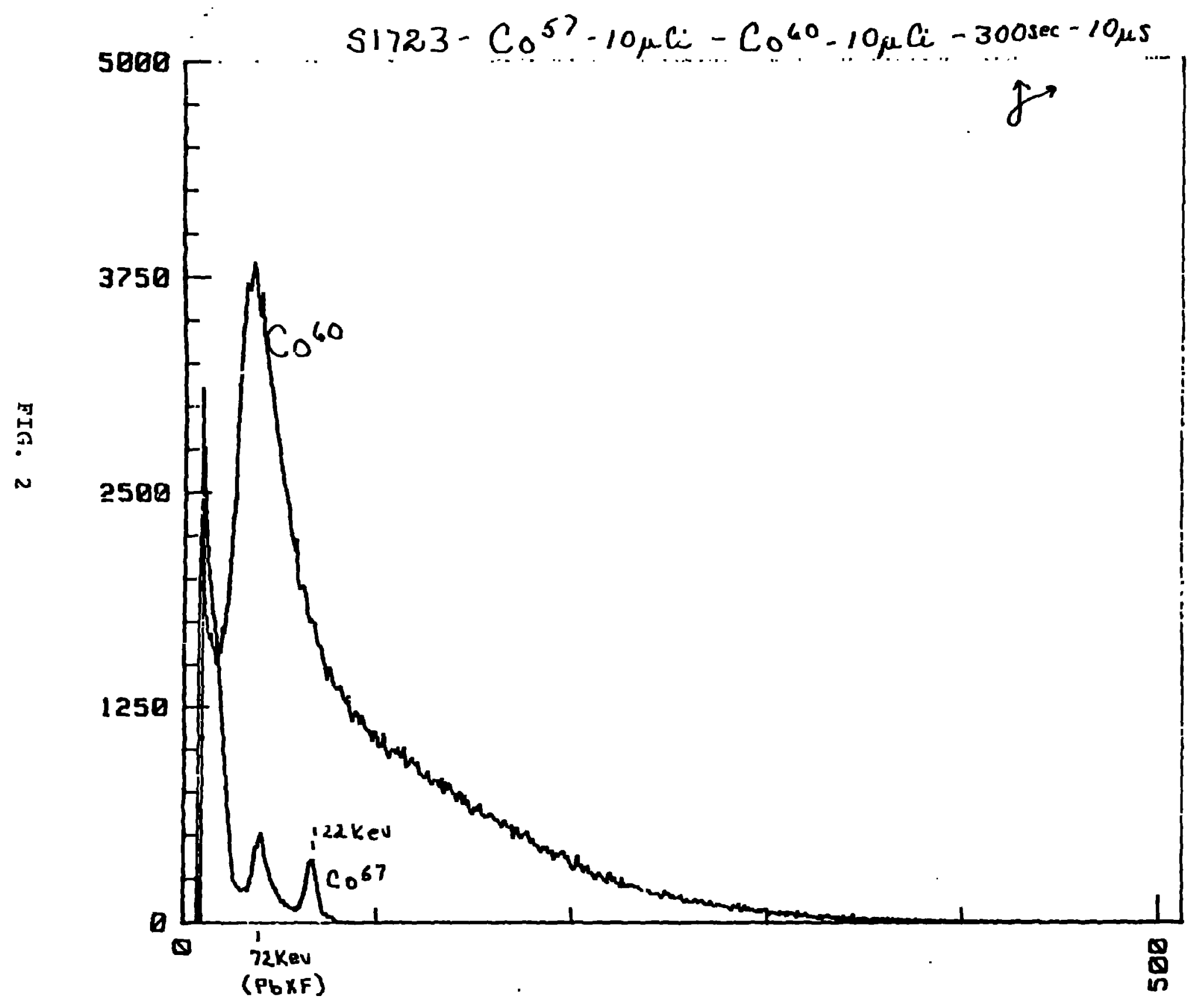

